\title{
The Map is Not Which Territory?: Speculating on the Geo-Spatial Diffusion of Ideas in the Arab Spring of 2011
}

\author{
Brian H. Spitzberg ${ }^{1}$, Ming-Hsiang Tsou ${ }^{2}$, Dipak K. Gupta ${ }^{3}$ Li An $^{2}$, Jean Mark Gawron ${ }^{4} \&$ Daniel Lusher ${ }^{2}$ \\ ${ }^{1}$ School of Communication, San Diego State University, USA \\ ${ }^{2}$ Department of Geography, San Diego State University, USA \\ ${ }^{3}$ Department of Political Science, San Diego State University, USA \\ ${ }^{4}$ Department of Linguistics, San Diego State University, USA \\ Correspondence: Brian Spitzberg, School of Communication, San Diego State University, San Diego, CA, 92182, \\ USA. E-mail: spitz@mail.sdsu.edu
}

Received: February 10,2013 Accepted: February 26, $2013 \quad$ Available online: April 12, 2013
$\begin{aligned} & \text { doi:10.11114/smc.v1i1.64 } \\ & \text { URL: http://dx.doi.org/10.11114/smc.v1i1.64 }\end{aligned}$

\begin{abstract}
The process by which social movements move through time and space can be understood as a process of innovation diffusion of memes or ideas. This process of diffusion may be traceable through computational linguistics and map geocoding of the linguistic memes employed by such movements. A Visualizing Information Space In Ontological Networks (VISION) method is described and illustrated with web-based search results of keywords relevant to Arab Spring. Using map algebra, and with the potential for using computational linguistics, the intent is to demonstrate the feasibility of both the theoretical model of diffusion, as well as the relevance of the geospatial dimension in understanding another dimension of diffusion - the meaning space of ideas as they spread through new media. Such methodology holds substantial promise for understanding the communicative dynamics of social movements and social influence.
\end{abstract}

Keywords: social movement, innovation diffusion, meme, geocoding, geolocation

If the traditional notion of space is three-dimensional, with time as a fourth dimension, then meaning-space presumably exists within this matrix of dimensions. The information content of cyberspace may consist of $1 \mathrm{~s}$ and 0 s, yet this information possesses potential for eliciting meaning in real space and real places. Theories such as diffusion of innovations represent a particular type of dimension in this meaning-space, a dimension of adoption of, or influence by, a given idea, often in the form of a social movement. The spread of an idea, such as the possibility of a more democratic life in a traditionally autocratic region or regime, can be understood as a vector over time, space, and meaning. Technologies are now available that are providing tools for visualizing such diffusion, and new methodologies and theories are needed to begin integrating our ideas with our investigative innovations. Some of the prospects of this integration are explored methodologically, with emphasis on the geo-spatial mapping and analysis of idea diffusion in web-based semantic contents, and conceptually, through an integration of diffusion of innovations theory. These ideas are illustrated in a case study of the geolocation of semantic concept diffusion in the Middle East during the early stages of the "Arab Spring" of 2011.

\section{Social Movements as Diffusion of Innovations}

"Social movements are variously defined, often hard to categorize, and —as a result of their 'unconstitutional' qualities-resistant to rigid theorizing" (Downing, 2008, p. 43). Social movements are "networks of informal relationships between a multiplicity of individuals and organizations, who share a distinctive collective identity, and mobilize resources on conflictual issues" (Diani, 2000, p. 387). Such mobilization may, but does not necessarily, take the form of protest events, and such protest events do not necessarily consist exclusively of members of a social movement. Protests are symbolic efforts to gain attention or change by engaging in deviant, disruptive, or highly noticeable activity. Movements involve planning and organizing, whereas protests may range from planned and organized to unplanned and disorganized. Both social movements and protests have as a core objective the pursuit of change in some aspect of the status quo, but social movements typically work within 
or at the boundaries of conventional mechanisms of change, whereas protests often engage means considered outside the conventional boundaries of legitimate political or societal change.

Numerous theories have been proposed to understand the origins and developmental patterns and processes involved in protests and social movements (e.g., Downing, 2008; Jensen, 2006; Meyer, 2004; Mitchell, 2004). Relatively early on it was recognized that among other things, the changes social movements sought could be considered forms of diffusion (Marquette, 1981; Strodhoff, Hawkins, \& Schoenfeld, 1985). A diffusion "is a special type of communication in which the messages are about a new idea" (Rogers, 2003, p. 6). The diffusion process, therefore, involves communicating an idea "through certain channels over time among the members of a social system" (Rogers, 2003, p. 5). An innovation is "an idea, practice, or object that is perceived as new by an individual or other unit of adoption" (Rogers, 2003, p. 12). When viewed as an idea or a linguistic phrase, diffusions can be considered as forms of "memes," which are analogous to cultural genes passed from one person, group, machine, or any entity to another (Heylighen \& Chielens, 2009).

There are distinguishable models (Meade \& Islam, 2006), paradigms (Earl, 2010; Greenhalgh et al., 2005), and theoretical limitations (Lundblad, 2003) of diffusion of innovations (DI) research, although its core concepts are relatively similar across disciplines and applications. In its original formulation, the theory relied in large part on information theory frameworks for conceptualizing communication as a process of convergence (Rogers \& Kincaid, 1981).Information theory is the foundation for all contemporary technologies of communication, as well as much of contemporary communication theory (Harrison, Todd, \& Lawton, 2008). Information is any variation in matter or energy that influences uncertainty in a context of alternative options or choices (Rogers \& Kincaid, 1981), whereas convergence is the degree to which communicators achieve similarity in meaning.

"A communication network consists of interconnected individuals who are linked by patterned flows of information" (Rogers \& Kincaid, 1981, p. 75).A broad array of developments has identified network roles (e.g., liaison, gate-keeper, etc.), actor-level constructs (e.g., degree, range or diversity, centrality, etc.), and network-level constructs (e.g., multiplexity, strength, stability, etc.) that define relationships, groups, and institutions (Monge \& Contractor, 2001; Watts, 2004). It is beyond the scope of this essay to synopsize network analysis, but a few insights into its relevance to social protest movements are in order.

Social networks are influenced, mapped, and enabled by both geospatial factors (e.g., proximity, mobility patterns, etc.) and media connectivity factors (Walther \& Bazarova, 2008). Several illustrative principles of networks suggest the potential for this framework to illumine the dynamics of social movements. First, certain power laws predict system behavior at macro levels (e.g., Li, 1992). For example, research confirms that despite (and perhaps in part because of) media connectivity, people's actual geospatial patterns of movement and communication across the course of a typical day are highly predictable en masse (Shaw \& Yu, 2009; Song, Qu, Blumm, \& Barabási, 2010; Yin, Shaw, \& Yu, 2011). Second, the small world hypothesis speculates that despite over six billion people on the planet, most people are only a few links apart from one another (Dodds, Muhamad, $\&$ Watts, 2003).

Third, the strength of weak ties hypothesis (Granovetter, 1973) speculates that weak ties are generally more influential to social and relationship outcomes than strong ties. Fourth, various studies of complex systems indicate threshold and cascade effects that may reflect the nature of system changes resulting from relatively small interim changes. So, for example, diffusions of ideas appear to be regulated by threshold effects in which people adopt new ideas or join emerging groups only when a certain percentage of their peers or the population have joined. These incremental steps can occur in logarithmic forms that appear dramatic (or catastrophic) at the macro level (Gupta, 2001). Some research indicates "global cascades can only occur when the influence network exhibits a 'critical mass' of early adopters, ... who adopt after they are exposed to a single adopting neighbor" or peer (Watts \& Dodds, 2007). Such changes are often masked because peers frequently engage in preference falsification, in which they misrepresent their views due to perceived social pressure, until a sufficient threshold of peers has adopted the actual preferred position (Kuran, 1989, 1995), thereby overcoming the natural inclination to free ride (Olson, 1968). Thus, the relative anonymity and mass access to new media may significantly alter the need of a population to engage in preference falsification, and the extent to which preference falsification can be interpreted by any given individual seeking to gauge the views of peers in a social milieu.

The implication of these five patterns (power laws, small world, weak ties, threshold effects, preference falsification) is that ideas have the potential to spread extensively from relatively isolated beginnings in people's relatively predictable patterns of social life. In contrast to most rhetorical or historical analyses, network theory directs attention to factors that often appear small in isolation, but have large systemic effects (e.g., Taleb \& 
Blyth, 2011). Communication processes are central to both perspectives, but in the network perspective, the power of communication is in its distributed systemic force. Research on a particular type of diffusion has illustrated the value of network perspectives - the spread of terrorist ideology and activity (Chenet al., 2008; Kennedy \&Weimann, 2011; Stohl \& Stohl, 2007).

New media holdmanifold ramifications for altering the public sphere of discourse (e.g., Kozinets, Valck, Wojnicki, \& Wilner, 2010). Original propositions about physical proximity that populated early versions of diffusion theory seem almost quaint in today's new media environment, and yet, geography still plays a central role in such human activities (Crandall et al., 2010; Erickson, 2010; Jones et al., 2008; Tillema, Dijst \& Schwanen, 2010; Yin et al., 2011). Furthermore, some of the original propositions of DI theory, such as the moderating role of homophily (i.e., similarity), may take on new importance in a realm in which media exposure and relationship formation can be highly selective in the context of a large field of availables (e.g., Watts, Dodds \& Newman, 2002).

At this juncture, it may be premature to consider falsificationist approaches to theory testing of innovation diffusion concepts through descriptive analyses of social media and internet content patterns. New media clearly provide a major window into real communication patterns that reflect, and perhaps produce, complex social activities. Given the various additional individual, group, institutional and communicative processes mediating social behavior, at best it seems likely that new media message patterns are only probabilistically related, rather than causally related, to social behavior. There are times when a given message (e.g., the Innocence of Muslims YouTube video) can be linked in relatively direct ways to large-scale social behavior, but such retrospective accounts still bear extraordinarily complex relations to predicting such behavior. Retrospective and prospective analyses of new media messages offer new opportunities to observe how message content flows and patterns relate to large-scale social activities. The correspondence between patterns of cyberspace messages and meanings and realspace social meanings in the form of behavior is likely to reveal probability functions that will inform future theory construction, and eventually theory validation.

New media not only facilitate diffusion processes, they are themselves a form of diffusion and may present a new repertoire of social movement tactics (Van Laer \& Aelst, 2010). This is important in developing countries in which new media adoption is still limited, such as in much of the Middle East and North Africa (Etling, Kelly, Faris, \& Palfrey, 2010). Various models have been proposed to account for individual and contextual factors in the adoption of new media. Research indicates that factors that parallel some of DI theory's key components, such as relative advantage (i.e., usefulness), complexity (i.e., perceived ease of use), and trial ability (i.e., usage), significantly affect new media diffusion and adoption (e.g., Wu \& Lederer, 2009). Uses and gratifications theory finds a complementary nexus with DI theory when the relative value of a diffusion is understood in the frame of the affordances, functions, uses, or gratifications that new media fulfill. Various theories and models have suggested that different affordances of ICT (e.g., Stephens, 2011) are moderated by the competence of the person employing those media (e.g., Spitzberg, 2006; Stephens, 2011). For example, social movement organization websites reveal six basic functions served by such media, and implicitly, by their hosting collective providers and participants: providing information, action and mobilization, fundraising and resources, lateral linkages, interaction and dialog, and creative expression (Stein, 2009; van den Hooff \& de Jonge, 2005).

The term "new media" can also be understood as a contemporary designation of a broader class of media referred to as information and communication technologies (ICTs) (Stephens, 2007, p. 488). The primary means through which (ICT) and new media will affect diffusion of ideas and social movements at the macro-level is the ability of such media to amplify the velocity (i.e., time) and reach (i.e., geography) of ideas (i.e., meaning) in and across human networks (Carty, 2010; Diani, 2000). Social movements are also likely to depend at the micro-level on the ICT competence of the people involved or recruited to the cause (Van Laer, 2010).

One of the affordances that new media offer is the facilitation of relational and collective activity. Geocoding and GPS tracking, social media, text messaging, and mobile access to web information allow people to communicate and coordinate their activities geospatially, and to a significant degree, to accomplish these functions in real time. This affordance is also a boon to scholars, as it permits entirely new forms of research methodology for the mapping of human communication activity (Shaw et al., 2009).

\section{Geospatial Mapping of Communication}

The discipline of geography is making major inroads in mapping the ecology of human communication. At least since Hägerstrand's (1966) study of geospatial diffusion of information and his (1970) articulation of geography's role in studying the space-time paths of individuals (see also Gale, 1972), the discipline of geography has pursued the scientific study of human activity patterns in time and space. This scholarly pursuit 
naturally led to what is now posited as a "communication geography" (Adams, 2010), in which the role of media and meaning are understood in relation to places (i.e., a local, more fixed, situation) and spaces (i.e., movement and mobility across places). The influence of place and space on communication activities, and the meanings that people place on place, are now part of the geographic canon (e.g., Jones et al., 2008).

Geographers are seeking to understand space not just in the familiar three dimensions of physical movement, but in the dimensions of time and meaning as well (Adams, 2010).The power of analyzing large-scale data sets based on people's use of landline and mobile phones provides extensive opportunity to model their types of communicative contacts in the context of their geospatial activities and movements (e.g., Shaw et al., 2009; Yin et al., 2011). One of the ways in which the communication of meaning and ideas can be studied is through the mapping of semantic constructs in time and space. One approach to pursuing this mapping involves the study of the geospatial diffusion of semantic ontologies on the world wide web (hereafter, the "web") and internet.

\section{Geospatial Mapping of Semantic Meaning-Space}

The web permits the expression of personal belief, attitude and value with the potential for widespread audience exposure. Its relative affordability, adaptability, and anonymity make it widely available to those with some access to the internet and relative regulatory freedom of speech. Through the expression and consumption of web-based content, ideas may diffuse through this communication process. Ideas may then provide some opportunity to identify group memberships based upon those who adhere to such ideas, and an opportunity to study how such group membership evolves over time. Analytical models and semantic ontologies can now efficiently crawl through the web and extract information on how certain ideas are expressed, and network linkage and traffic patterns can be studied to better understand how the group affiliations to such ideas diffuse and develop. Furthermore, to the extent that such messages can be geocoded (i.e., located by latitude and longitude or $\mathrm{X}$ and $\mathrm{Y}$ coordinates), such diffusion can be situated and mapped across time and space. Cyberspace can increasingly be located in realspace. In essence, the potential now exists that the diffusion of ideas associated with meaning space (e.g., social movements) can be efficiently and contemporaneously mapped across the dimensions of time and physical space.

Social movements emerge and are maintained through communication processes that help define group membership. Such identification processes are essential not only to facilitate the cohesion of the group, but to facilitate group motivation rhetorically by defining "other" groups, such as the "enemy" (Gupta, 2001, 2008). It seems reasonable to assume that a system of shared reference is one important signal of group identity, and shared references may have both positive and negative valences. That is, a group is to a significant degree defined by the existence of a collective system of shared references to persons, texts, events, or groups, which have a strong positive or negative affect for the in-group, as well as parallel semantic constructions for demonized out-groups.

Identification of such valences, and thus, group affiliations, requires an analysis of verbal content. Each word and phrase in a document (e.g., a web page) possesses a vector that represents other words and phrases with which it co-occurs (Dagan, Lee, \& Pereira, 1999). The most salient co-occurring words are modifiers that occur at statistically significant rates (Lee, 1997, 1999; Lin, 1998a, 1998b). When strongly negative vocabulary co-occurs with some referring expression $\mathrm{E}$ at a significant rate, it is evidence that $\mathrm{E}$ has a strong negative affect (Li \& Wu, 2010). The basis for assuming such expression as a marker of group membership is strengthened to the extent that network-based evidence (e.g., linkage analysis) reveals that E co-occurs more with similar group-identified members than with out-group members (Mullen, Migdal, \& Hewstone, 2001; Ohsawa, Soma, \& Matsuo, 2002). The result of developing a semantic list of terms and phrases through thesaurus-building (Grefenstette, 1994) that operationalize a communicative construct such as group membership is referred to as a semantic ontology. Initial confirmations can then be bootstrapped in the refining of a given semantic ontology by both demonstrating correct identification of group affiliations (Gawron et al., 2012), as well as expanding and correcting the ontology as the language of group membership itself evolves (Zhitomirsky-Geffet \& Dagan, 2009). For example, although the phrase "Jasmine Revolution" originally was coined to refer to the 1987 Tunisian transition of power, it was popularly recycled in early 2011 when uprisings again began in Tunisia. When unrest began springing up in the spring of 2011 in other Arab countries, the term was broadened to the new metaphor of the Arab Spring (الثور|تالعربية"; literally the Arabic Rebellions or the Arab Revolutions," Wikipedia, http://en.wikipedia.org/wiki/Arab_Spring). In the context of revolutionary social movements, reform-motivated groups would be likely to construct online content related to such identifying monikers, whereas groups and institutions motivated to preserve current authority structures might be inclined to avoid legitimizing reform movement by avoiding the use of such terms. 
Semantic ontologies have been powerfully applied to understanding various forms of complex ordinary written language usage, such as complaint processes (Galitsky, de la Rosa, \& Kovalerchuk, 2011), negotiation strategies (e.g., Rahwan, Sonenberg, Jennings, \& McBurney, 2007), and terrorist ideology (Qin, Zhou, Reid, Lai, \& Chen, 2007). The feasibility of using such techniques for understanding the structure and development of social movements has begun. For example, Zimbra, Abbasi and Chen (2010) outline a cyber-archaeology of social movement research that proceeds along four steps: (a) identification of virtual communities and cyber-artifacts; (b) cyber-artifact collection; (c) cyber-artifact classification; and (d) network analysis and visualization. They identify several stylistic (e.g., number of words, count of letters, vocabulary richness, grammatical word functions, etc.), structural (e.g., greeting type, URL presence, number of paragraphs, html tags, etc.), and topical (e.g., bag-of-words ontologies) variables that can be mined from existing ICT devices and domains. Other metrics of semantic relevance can also be calculated (e.g., Corman, Kuhn, McPhee, \& Dooley, 2002). Observing the diffusion of such information, semantic forms, tactics and protest aphorisms can provide significant insight into the nature of social movements (Earl, 2010). Over time, the relative value-added of the information provided by such data-mining methods can be assessed, and techniques and procedures refined for future applications (Meeks \& Dasgupta, 2004).

\section{The Geography of the 2011 Arab Spring}

As an initial foray into demonstrating the potential for geospatial mapping the diffusion of semantic content, a case example of the Arab Spring is presented. In order to contextualize this example, a brief overview of the Arab Spring is in order. In mid-December of 2010, in the Tunisian city of SidiBouzid, a street vendor named Mohammed Bouazizi set himself on fire in protest of what he claimed was police corruption and confiscation of his goods. He died in January as a result of his immolation. Protests escalated in Tunisia, and soon after, some level of civil unrest and protest emerged in Algeria, Jordan, Mauritania, Sudan, Oman, Saudi Arabia, Egypt, Morocco, Yemen, Iraq, Bahrain, Libya, Lebanon, Syria, Kuwait, and the borders of Israel (Blight \& Pulham, 2011; http://en.wikipedia.org/wiki/Arab_Spring). As of July 2011, The Economist estimated that almost 2,500 people had died in the protests. The co-occurrence of so much unrest, in what had been relatively stable and often autocratically and coercively maintained states, in so short an amount of time, led to a widely adopted characterization of an "Arab Spring," which collectively was considered a reflection of pro-democratic ideologies being spread by an upwelling of perceived deprivation, lack of reform, and lack of basic freedoms and economic security among the non-elite masses.

The Middle East represents approximately three percent of the world's internet usage (http://www.internetworldstats.com/stats5.htm). Yet, many commentators predicted significant political shifts in the Arab region due to ICTs (e.g., Etling et al., 2010; Khamis \& Šisler, 2010; Murphy, 2006), and others have since suggested that new media made a decisive difference in enabling the genesis and flowering of the Arab Spring (Bartholet, 2011). As Howard and Hussain (2011) opined:

Seeing what has unfolded so far in the Middle East and North Africa, we can say more than simply that the Internet has changed the way in which political actors communicate with one another. Since the beginning of 2011, social protests in the Arab world have cascaded from country to country, largely because digital media have allowed communities to unite around shared grievances and nurture transportable strategies for mobilizing against dictators. (p. 48)

Other commentators have cautioned against attribution of the Arab Spring to media 2.0 (Anderson, 2011; Northedge, 2011), and cautioned that the internet can facilitate revolution, butalso distract, distort, repress and thereby counteract such social change (Morozov, 2011).

Given that the Arab Spring is still in process in several locations in Northern Africa and the Middle East, there may be insufficient opportunity, even in hindsight, to comprehend the dynamics involved in each particular set of protests and movements (El-Mahdi, 2009). Those familiar with this region of the world generally conclude that each country and each social movement within those countries has its own local circumstances, religious fractures, economic constraints, and political aims, which makes generalizations about the role of new media very tentative, and perhaps necessarily invalid when generalized or simplified (e.g., Cottle, 2011). Add to this the dynamic cascading effects of seemingly minor events or actions (Taleb \& Blyth, 2011), and it seems a daunting task to seek general explanations for the Arab Spring. Still, although "the immediate catalysts for these protests differ,.... their overall intent is the same. The protests mean to signal sharp dissatisfaction with the depth and pace of change" (The Economist, 2011, p. 48).

\section{A Case Study of Arab Spring}

\subsection{Methodology}


The methodology described here is a new set of techniques for web search and web content analysis, which will be referred to as the Visualizing Information Space In Ontological Networks (VISION, see Figure 1). To date, most approaches to mapping idea content on the web have focused more on cyberspace than on realspace. The actual physical location of such information is typically viewed as inaccessible, irrelevant or as relatively unimportant (e.g., Chen et al., 2008). Those approaches that do utilize geolocation tend to have relatively narrow constraints. For example, Google Trends analyzes input keywords rather than web content- thereby reflecting people's curiosity about ideas, but not necessarily the nature of the ideas stimulating, informing, or resulting from those queries (Guo, Zhang \& Zhai, 2010). Numerous online data-mining methodologies examine various data sources, including linkage analysis (e.g., Chen et al., 2008), emails (e.g., Matsumura \& Sasaki, 2007), blogs (e.g., Chau \& Xu, 2007), Twitter tags (e.g., Etling et al., 2010), and websites (e.g., Elmer, 2006). The VISION method seeks to connect verbal contents of webpages to geolocated time and space coordinates.

VISION begins with software-based web-crawlers or web robots, which systematically seek certain search parameters in publicly available databases or sources. Web crawlers are dynamic programs that collect and duplicate information targeted in their search parameters inputs. The web crawler can switch websites based on the hyperlinks, typically in the Hyper Text Markup Language (HTML).The crawler will return webpage information ranked by the keyword search algorithms of whichever search engine is used. In returning information about any given website, the crawler can access the website's Internet Protocol (IP) address, which is associated with a domain name. Geolocation can be extracted from IP addresses by accessing the registration information of the person or entity "at" that IP address. This registration information includes a physical address of the registrant (i.e., not the host server, but the IP registrant for that site). This address information is then processed by a WHOIS database server, which extracts the latitude and longitude of the address, information maintained by Regional Internet Registries (RIR), such as the American Registry for Internet Number (ARIN) or Asia-Pacific Network Information Centre (APNIC).

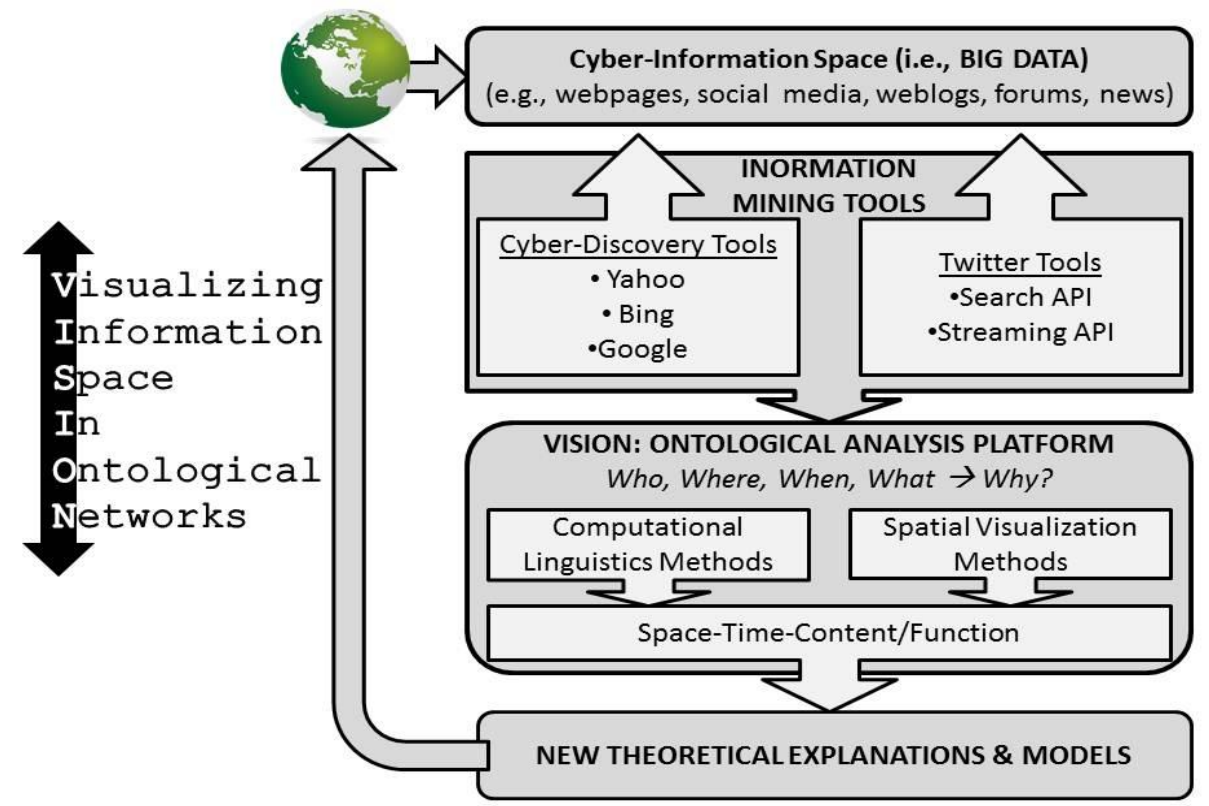

Figure 1. Visualizing Information Space In Ontological Networks

The search terms directing the web crawlers therefore return relevant URLs ranked by the main search engine being used (e.g. Yahoo, Google, Bing, etc.), and their associated density of registrant latitude and longitudes, and these data are compiled in an Excel file, representing up to the top 1000 hits. This data set is then uploaded into a Geographic Information Systems (GIS) software such as ESRI ArcGIS, and converted to visualization maps. What is translated onto the map is a set of point data representing the density of the occurrence of the search words or phrases on a standard digital geographic image map. Preliminary analyses by our research team suggests that approximately 10 to 12 percent of address locations are unmatchable or in error, although the mismatch rates are likely to vary from one domain topic or social activity to another. 
There are several types of information landscapes that can be analyzed once the data are converted to map coordinates. For example, to date our research team has examined the utility of the following constructs. First, assuming data bases are available, it is possible to control for population density by subtracting the population size of the geospatial areas on the map from the point density of the URLs (i.e., population standardization). Second, it is possible to control for semantic usage frequency by subtracting a frequency-based set of the 300 most common words in English language usage, thereby providing a measure of search terms occurring on a website more than would be expected by chance word occurrence (semantic standardization). Third, it is possible to assess the difference between the point-density of any two maps, which permits a comparison of search terms (i.e., semantic delta map) or times of search (i.e., chronological delta map). These maps reflect the extent to which a given search term shows up with greater density relative to another search term, or the degree to which a search term shows up with greater density at one time relative to another time. Furthermore, to assist interpretation, the kernel density (i.e., the granularity of data) and radius threshold (i.e., number of standard map units included in the image - e.g., zip code level vs. county level vs. state level vs. country level, etc.) of maps can be adjusted. Such differences follow standard geographic raster-based map algebra:

\section{Differential Value $=($ Keyword-A / Maximum-Kernel-Value-of-Keyword-A $)-($ Keyword-B $/$ Maximum-Kernel-Value-of-Keyword-B)}

In each search translation into map form, the kernel densities can be represented by varying color ramps indicating which areas of the map display higher relative to lower densities. In the delta maps, the colors can represent the relative direction of change from one map to the next. The result of these mapping procedures, certain search terms and formations may be said to represent spatial fingerprints of the concept under study. Some spatial fingerprints of the Arab Spring are presented as illustrations of this method.

Some key dates in the Arab Spring can serve as reference points. On December 19, 2010, the street vendor set himself on fire in Tunisia. By January 16, 2011, the Tunisian president had fled to Saudi Arabia. As of January 29, Egyptian President Hosni Mubarak had just appointed his intelligence chief as the first ever Vice President in order to establish an orderly plan of succession. A pledge to step down at the next election was not offered until February 1. By the11th, Mubarak agreed to stand down and hand power over to the military.

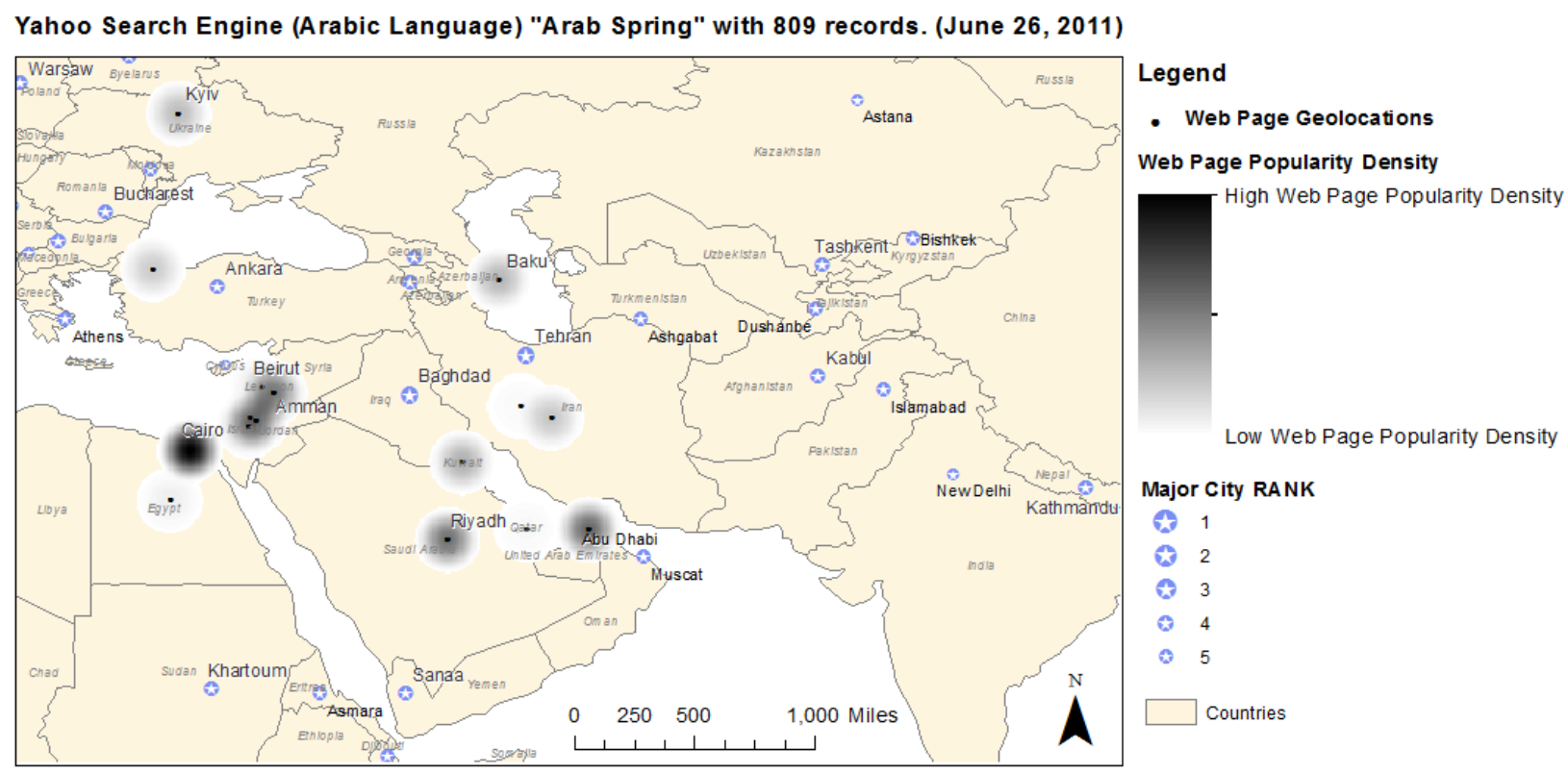

Figure 2. Regionally-Framed Yahoo search of "Arab Spring” [Arabic] on June 26, 2011 ( $n=809$ records)

Figure 2 illustrates a screen shot of the results of a search for the keywords "Arab Spring" in Arabic (using Google translate, search not case sensitive), using GIS software to convert web pages into geolocations within the Middle East region. Some areas reveal obvious hotspots of web content regarding the Arab Spring, including the geopolitical nexus among Jerusalem (Israel), Amman (Jordan), Damascus (Syria), and Beirut (Lebanon), as 
well as Riyadh (Saudi Arabia) and Abu Dabhi (United Arab Emerates). The keywords, however, also show up to some degree in some areas that are less expected, such as Baku (Azerbaijan).

Yahoo Search Engine (Arabic Language) "A rab Spring" with 805 records. (July 03, 2011)

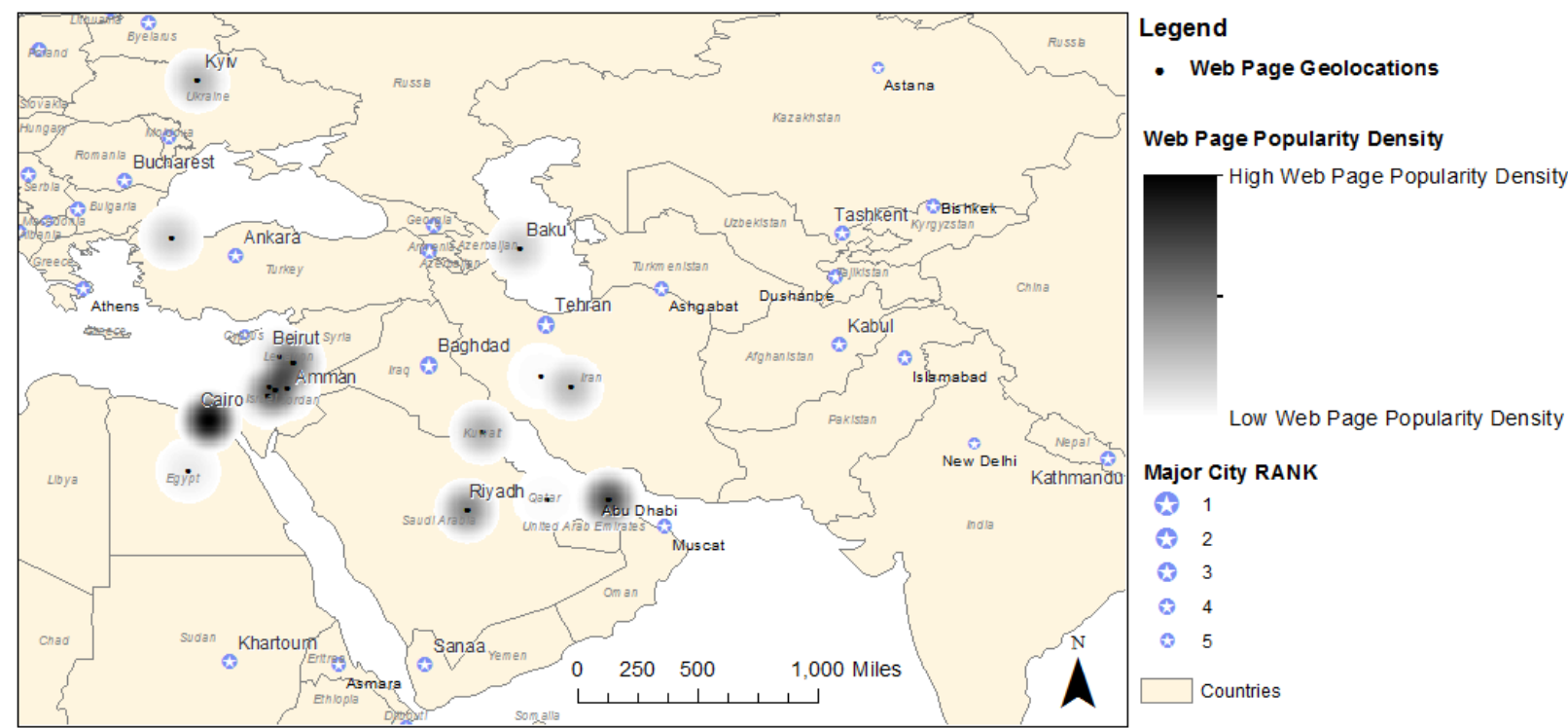

Figure 3. Regionally-framed Yahoo Search for "Arab Spring” [Arabic language] on July 3, $2011(n=847$ records)

Figure 3 shows a search of the same keyword, "Arab Spring," in Arabic merely a little more than a week later. Comparison by just "looking" at the two maps reveals little obvious difference. When map algebra is applied, however, to subtract the digital densities of Figure 2 from Figure 3, the result illustrates a number of obvious differences in the diffusion of ideas. Specifically, as displayed in Figure 4, the density of Arabic web content significantly increased in the politically volatile areas surrounding Damascus, Amman, Beirut and Jerusalem, as well as in Istanbul, around Abu Dabhi. Over the same time period, interest seemed to wane slightly in Riyadh, Qatar, and Baku.

\section{Yahoo Search Engine (Arabic Language) "Arab Spring" Comparison between June 26 and July 03, 2011.}

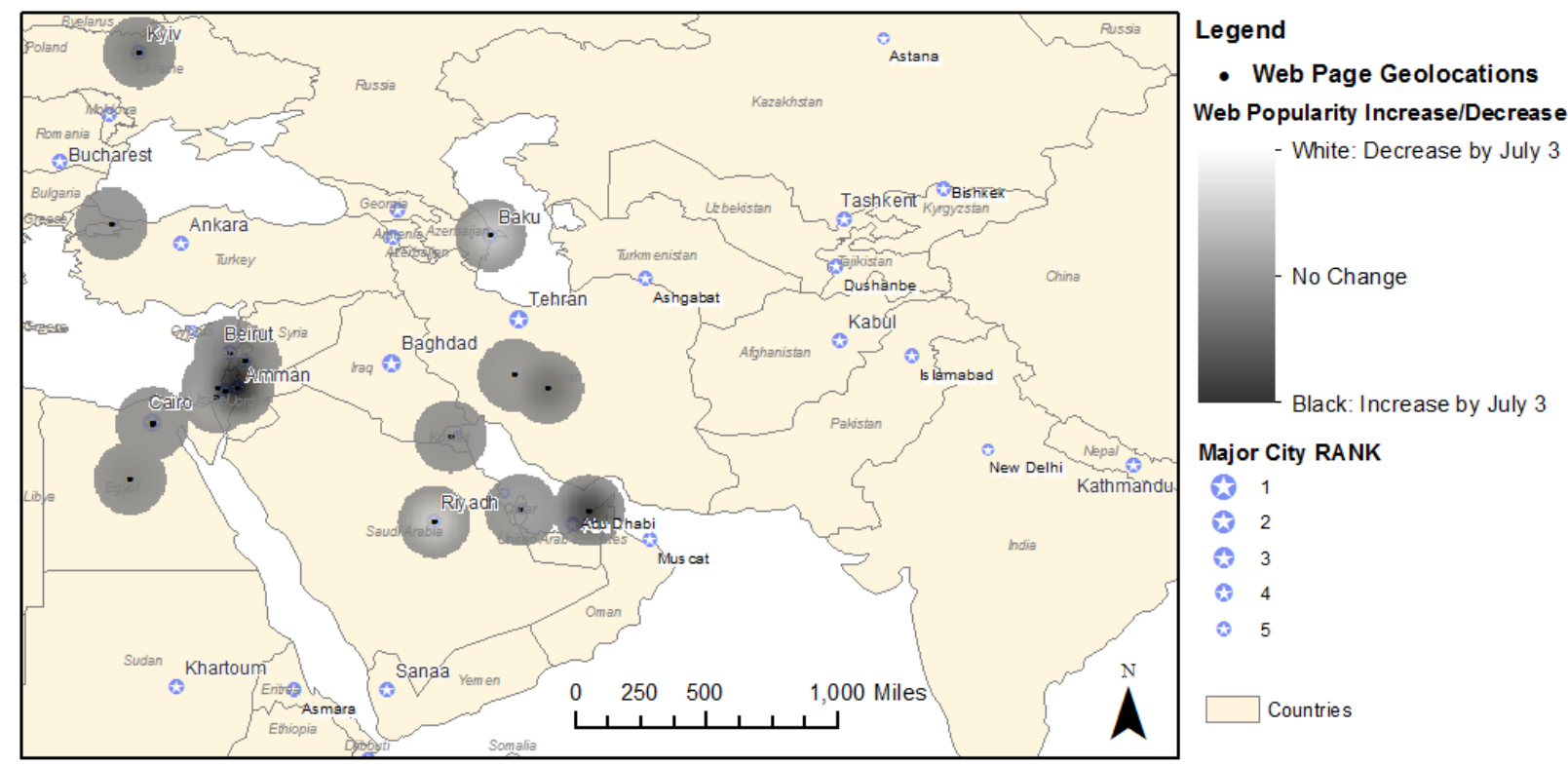

Figure 4. Regionally-Framed Yahoo Search of “Arab Spring” [Arabic]; Chronological-Delta of June 26 vs. July 3, 2011 
While it is not possible to explore potential narratives for all of these changes, a few conjectures can be derived from the popular press. For example, in Jerusalem civil protests regarding economic issues may have been linked to the Arab Spring as having a common dissatisfaction with political progress on economic issues. Syria found itself embroiled not only in a coercive crackdown on its escalating public protests for reform, but also a subject of increased international pressure for reform or regime change. Jordan is considered a more stable and moderate-progressive state than most of its Arab neighbors, but during this time they were experiencing increased new media protests for reforms (Luck, 2011). Abu Dhabi, with its large proportion of expatriates from other Arab countries and relative wealth and political stability may simply reflect a more open political curiosity and interest in its neighbors. The decreased interest in Riyadh, in contrast, may reflect a relative ephemeral concern over such issues, given that after March 11, Saudi Arabia banned public protests, but by March 18, King Abdullah announced and began instituting a variety of economic proposals, including hiring 60,000 of its citizens as security forces, and billions in salary increases, housing, and so forth. The decreased interest in Baku may reflect that on March 11, a Facebook site was developed in Azerbaijan to generate interest in regime change, with over 4,000 supporters. The government reacted in May to street protests by arresting and jailing many protesters.

Yahoo Search Engine (English Language) "Arab Spring" comparison between June 26, 2011 and July 03,2011

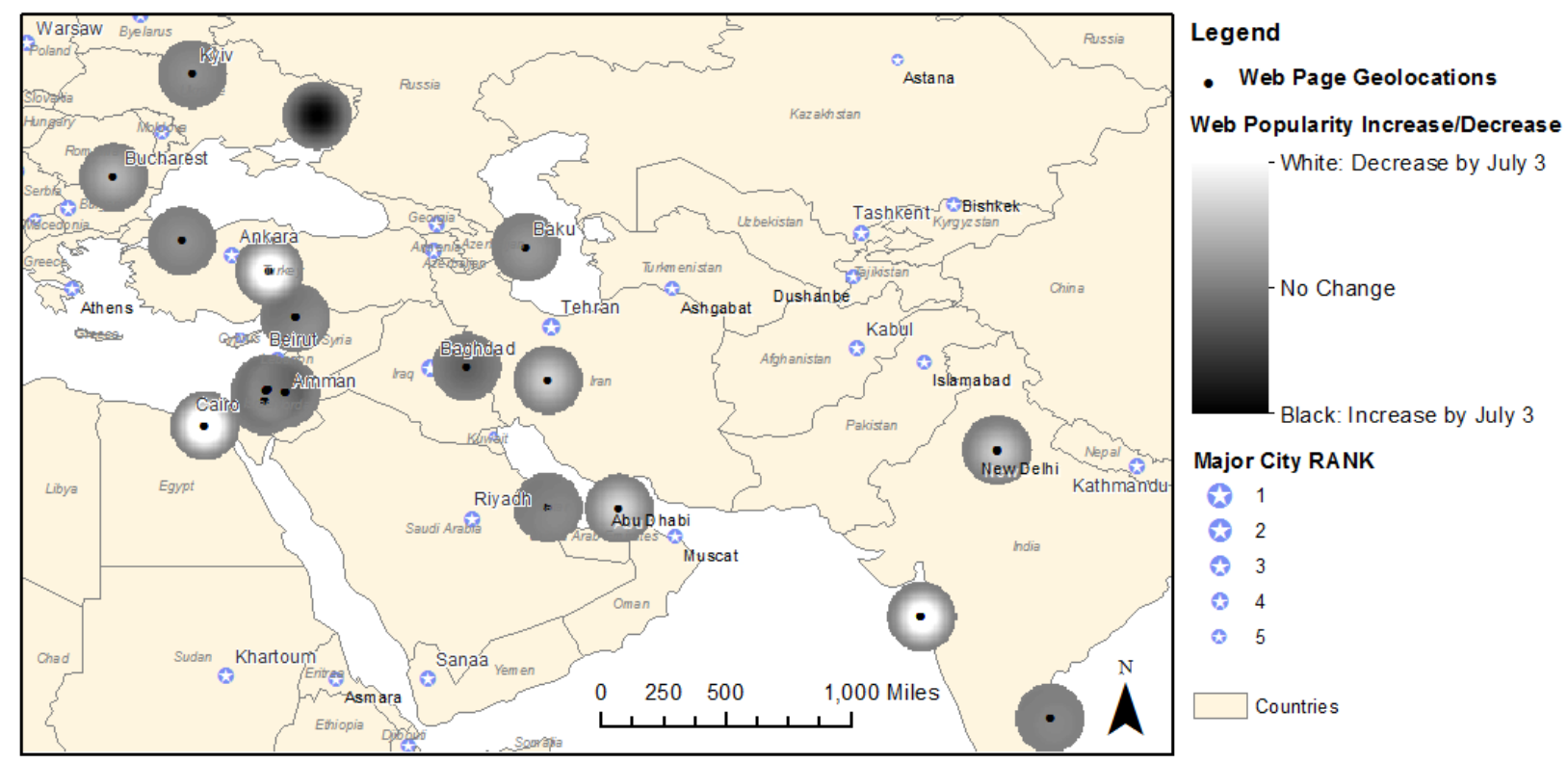

Figure 5. Regionally-Framed Yahoo Search for "Arab Spring” [English Language] Chronological Delta Map for June 26 to July 3, 2011.

When the same search procedures are applied using English instead of Arabic, a different pattern of diffusion results. As shown in the chronological delta map in Figure 5, Damascus, Amman, Beirut and Jerusalem show an increased density of interest in "Arab Spring" than their neighbors, and specific hot spots show up in Baghdad, and in the Donetsk area of the Ukraine. In contrast, Cairo shows decreased interest in the topic, along with Abu Dhabi, Mumbai and New Delhi in India, the Kayseri area in Turkey, and in Bucharest, Romania. Thus, not surprisingly, idea diffusion processes clearly are somewhat language-specific, in that India shows interest in concepts in English but not in Arabic. Further, there may be very local events that influence diffusion processes. For example, in July there was a conference held for Women's Learning Partnership for Rights, Development and Peace, discussing as a major theme the impact and potential of the Arab Spring for women's interests in the Middle East.

Illustrating the potential influence of evolving language and time in diffusion processes, Figure 6displays a chronological delta map for the English keywords "Jasmine revolution." This map shows a longer time period for diffusion to occur - over a month. A much more variegated map results, with increased interest in revolution in Istanbul, Ukraine, Eastern Europe, and in several locations in India, although New Delhi and Sri Lanka, along with the Amman-Damascus—Jerusalem/Tel Aviv areas, reveal significantly diminished interests in this topic during this time. 
Yahoo Search Engine (English Language) "Jasmine Revolution" comparison between Feb 03, 2011 and March 24, 2011

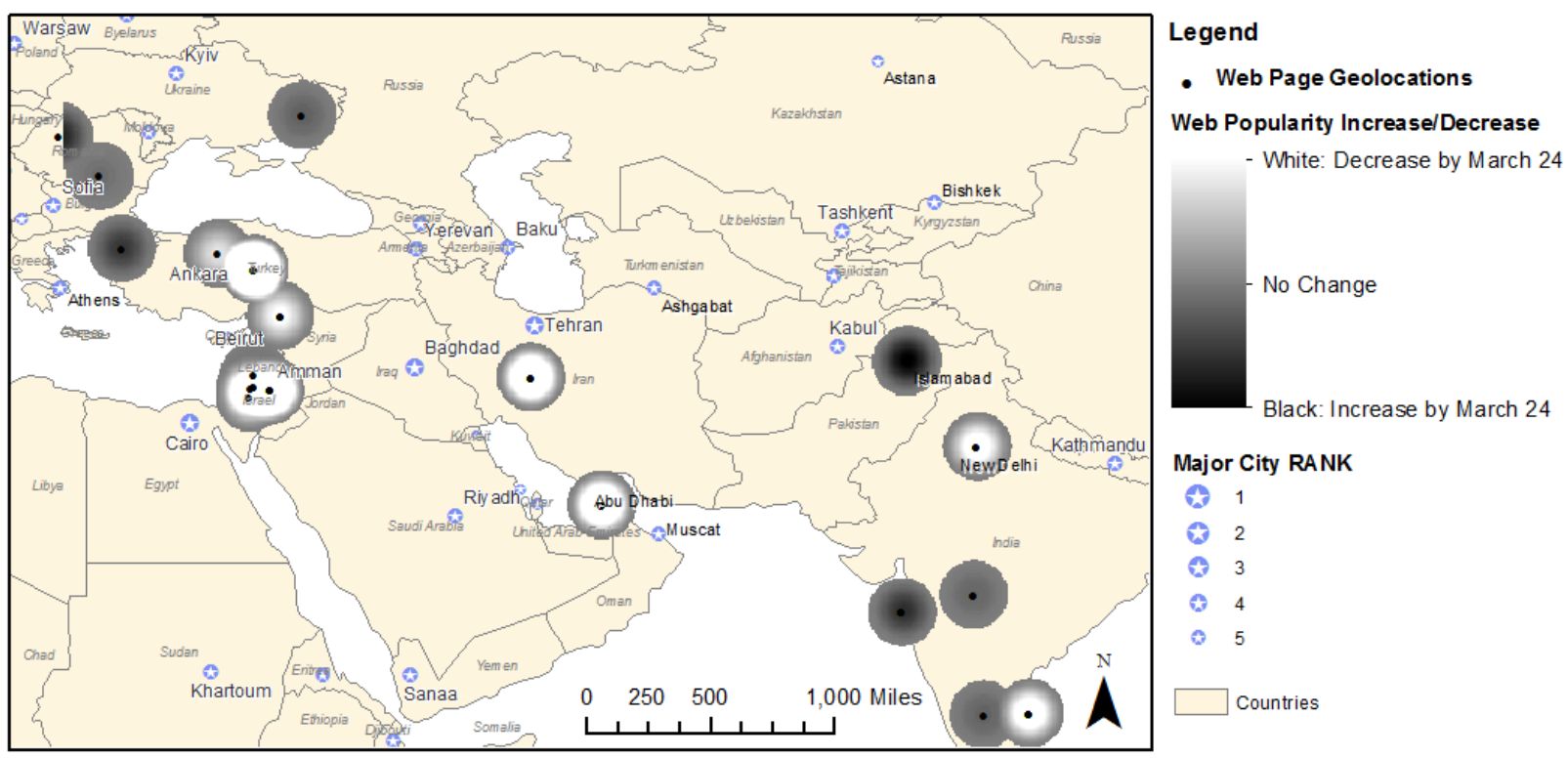

Figure 6. Regionally-Framed Yahoo Search for "Jasmine Revolution" [English] Chronological Delta Map for February 3 to March 24, 2011

A map such as this suggests the powerful effect of local contextual factors in affecting diffusion. Different locales may scavenge the memes of evolving social movements based on local circumstances. Earl (2010) analogizes online social movements to disease diffusion: "When diseases jump sub-populations, moving from better-studied sub-populations to unstudied sub-populations, understanding the social habits and social organization of the sub-population to which the disease jumped is important" (p. 218). The kinds of density shifts revealed by these geospatial maps reflect more than just a lone web site or two in a given area. These kinds of shifts represent dozens to hundreds of website shifts in idea content. As the computational linguistics involved in identifying specific language representations of ideas become more refined, and the software involved in geolocating and visualizing such verbal content becomes more integrated, it should be possible to study the diffusion of ideas in time and space in ways that reveal the process in extraordinary detail. To the extent that the key rhetorical tropes of a social movement can be uniquely identified, the diffusion of these tropes across time and now space becomes possible.

\subsection{Of Messages, Meaning, Media, and Maps}

Throughout history, major changes in communications technologies have ushered in significant changes in human activity. Most of these diffusion curves co-occurred with many other societal and technological changes, and thus, the extent to which the changes in ICTs ultimately changed the nature of communication itself is difficult to determine. Despite massive increases in the diffusion of new media, for example, scholarly research continues to understand the uses of these media primarily through the lenses of existing theories (Lee, Kim, \& Rosen, 2009). It seems that the medium never was the message-it was at most merely one of several moderators of the ability of the content of communication to effect change and create convergence (or divergence). Technologies changed the velocity, the capacity, and the efficiency of communication, but probably had relatively little effect on what communication is, and needs to be, used for. Seven million years of primate evolution shaped the functions to which communication processes were adapted (Kock, 2009; Osgood, 1969) - such functions are unlikely to be transformed in a mere millennium of new technological affordances. That is, the fundamental nature of communication involves some rather basic adaptive functions: the reduction of uncertainty, the control of one's environment, the coordination of collective human activity, the expression of inner thought, the selection of mates and development of attachments, and the convergence and divergence of individuals and groups (Bugental, 2000). Technologies of communication merely provide better affordances for achieving such functions.

Transformation of human systems still depends substantially on human factors. Despite revolutions and civil unrest in several countries throughout North Africa and the Middle East, some of these revolutions are revealing ongoing developmental disturbances and evolutions. Some have been relatively bloodless, and others find that 
there is no communicative substitute for blood. Furthermore, no amount of technology will substitute for an unruly crowd of thousands experiencing coercive treatment from a coercive regime. Media do, however, stimulate and facilitate certain organizing processes, and vicariously diffuse the experiences of such groups, thereby potentially amplifying the diffusion of the protest's or movement's message.

Identifying the moderating roles that media play in the development of such social movements and protests has been a significant theoretical and methodological challenge. New media have ushered in not only important mechanisms for facilitating such movements, but have provided scholars new ways of studying and understanding the role that these media play in the evolution of protest and social and political change. As such, the media themselves provide an important reflective technology for humans to understand how humans use media. In the process, as they have throughout history (e.g., writing, printing press, telegraph, television, internet, social media), they are redefining the concept of space. As with Einstein's paradigmatic redefinition of space near the turn of the $20^{\text {th }}$ century, redefining human space in the $21^{\text {st }}$ century will allow new questions to be asked, and will demand new approaches to answering these questions.

\section{Acknowledgements}

This material is based upon work supported by a grant by the National Science Foundation Division of Computer and Network Systems, NSF Program CDI-Type II Award \# 1028177. Opinions expressed are those of the authors and not necessarily those of the National Science Foundation.

http://www.nsf.gov/awardsearch/showAward.do?AwardNumber=1028177

The authors would like to acknowledge the contributions in data collection, processing, and mapping provided by Jennifer Smith and Luke Kemper

\section{References}

Adams, P. C. (2010). A taxonomy for communication geography. Progress in Human Geography, 35(1), 37-57. http://dx.doi.org/10.1177/0309132510368451

Anderson, L. (2011). Demystifying the Arab Spring: Parsing the differences between Tunisia, Egypt, and Libya. Foreign Affairs, 90(3), 2-7.

Bartholet, J. (2011).Young, angry, and wired.National Geographic, 220(1), 102-107.

Blight, G., \& Pulham, S. (2011). Arab spring: An interactive timeline of Middle East protests. The Guardian. Available: http://www.guardian.co.uk/world/interactive/2011/mar/22/middle-east-protest-interactive-timeline

Bugental, D. B. (2000). Acquisition of the algorithms of social life: A domain-based approach. Psychological Bulletin, 126(2), 187-219. http://dx.doi.org/10.1037/0033-2909.126.2.187

Carty, V. (2010). New information communication technologies and grassroots mobilization. Information, Communication and Society, 13(2), 155-173.

Chau, M., \& Xu, J. (2007). Mining communities and their relationships in blogs: A study of online hate groups. International Journal of Human-Computer Studies, 65(1), 57-70. http://dx.doi.org/10.1016/j.ijhcs.2006.08.009

Chen, H., Qin, J., Reid, E., Zhou, Y., \& Sageman, M. (2008). Case study of jihad on the web: A web mining approach. In H. Chen, E. Reid, J. Sinai, A. Silke, \& B. Ganor, (Eds.), Terrorism informatics: Knowledge management and data mining for homeland security (pp. 221-236). New York, NY: Springer.

Corman, S. R., Kuhn, T., McPhee, R. D., \& Dooley, K. J. (2002). Studying complex discursive systems: Centering resonance analysis of communication. Human Communication Research, 28(2), 157-206. http://dx.doi.org/10.1093/hcr/28.2.157

Cottle, S. (2011). Media and the Arab uprisings of 2011: Research notes. Journalism, 12(5), 647-659. http://dx.doi.org/10.1177/1464884911410017

Crandall, D. J., Backstrom, L., Cosley, D., Suri, S., Huttenlocher, D., \& Kleinberg, J. (2010). Inferring social ties from geographic coincidences.Proceedings of the National Academy of Sciences, 107(52), 22436-22441. http://dx.doi.org/10.1073/pnas.1006155107

Dagan, I., Lee, L., \& Pereira, F. C. N. (1999). Similarity-based models of word co-occurrence probabilities. Machine Learning, 34, 43-69.

Diani, M. (2000). Social movement networks: Virtual and real. Information, Communication and Society, 3(3), 386-401. http://dx.doi.org/10.1080/13691180051033333 
Dodds, P. S., Muhamad, R., \& Watts, D. J. (2003). An experimental study of search in global social networks. Science, 301(5634), 827-829.

Downing, J. (2008). Social movement theories and alternative media: An evaluation and critique. Communication, Culture and Critique, 1(1), 40-50. http://dx.doi.org/10.1111/j.1753-9137.2007.00005.x

Earl, J. (2010). The dynamics of protest-related diffusion on the web. Information, Communication and Society, 13(2), 209-225. http://dx.doi.org/10.1080/13691180902934170

The Economist. (2011, July 16). Revolution spinning in the wind; The Arab awakening, 400(8742), 47-49.

El-Mahdi, R. (2009). Enough! Egypt's quest for democracy.Comparative Political Studies, 42(8), 1011-1039.

Erickson, I. (2010). Geography and community: New forms of interaction among people and places. American Behavioral Scientist, 53(8), 1194-1207. http://dx.doi.org/10.1177/0002764209356250

Etling, B., Kelly, J., Faris, R., \& Palfrey, J. (2010). Mapping the Arabic blogosphere: Politics and dissent online. New Media and Society, 12(8), 1225-1243. http://dx.doi.org/10.1177/1461444810385096

Gale, S. (1972). Some formal properties of Hägerstrand's model of spatial interactions. Journal of Regional Science, 12(2), 199-217.

Galitsky, B., de la Rosa, J-L., \& Kovalerchuk, B. (2011). Discovering common outcomes of agents' communicative actions in various domains. Knowledge-Based Systems, 24(2), 210-229. http://dx.doi.org/10.1016/j.knosys.2010.06.004

Gawron, J. M., Gupta, D., Stephens, K., Tsou, M. H., Spitzberg, B. H., \& Li, A. (2012). Using group membership markers for group identification. Proceedings of the Sixth International AAAI Conference on Weblogs and Social Media (ICWSM). Menlo Park, CA: AAAI Press. Available: http://www.aaai.org/Library/conferences-library.php

Granovetter, M. S. (1973). The strength of weak ties. American Journal of Sociology, 78(6), 1360-1380.

Greenhalgh, T., Robert, G., Macfarlane, F., Bate, P., Kyriakidou, O., \& Peacock, R. (2005). Storylines of research in diffusion of innovation: A meta-narrative approach to systematic review. Social Science and Medicine, 61(2), 417-430. http://dx.doi.org/10.1016/j.socscimed.2004.12.001

Grefenstette, G. (1994). Explorations in automatic thesaurus discovery. New York, NY: Springer.

Guo, S., Zhang, G., \& Zhai, R. (2010). A potential way of enquiry into human curiosity. British Journal of Educational Technology, 41(3), E48-E52. http://dx.doi.org/10.1111/j.1467-8535.2009.00949.x

Gupta, D. K. (2001). Path to collective madness: A study in social order and political pathology. Westport, CT: Praeger.

Gupta, D. K. (2008). Understanding terrorism and political violence: The life cycle of birth, growth, transformation and demise. New York: Routledge.

Hägerstrand, T. (1966). Aspects of the spatial structure of social communication and the diffusion of information. Papers in Regional Science, 16(1), 27-42.

Hägerstrand, T. (1970). What about people in regional science? Papers in Regional Science, 24(1), 7-24.

Harrison, S. J., Todd, Z., \& Lawton, R. (2008). Talk about terrorism and the media: Communicating with the conduit metaphor. Communication, Culture and Critique, 1(4), 378-395. http://dx.doi.org/10.1111/j.1753-9137.2008.00031.x

Heylighen, F., \& Chielens, K. (2009). Cultural evolution and memetics. In R. A. Meyers (Ed.), Encyclopedia of complexity and system science (pp. 3205-3220). New York: Springer.

Howard, P. N., \& Hussain, M. M. (2011). The upheavals in Egypt and Tunisia: The role of digital media. Journal of Democracy, 22(3), 35-48.

Internet World Stats. (2011). Internet usage in the Middle East. Available: http://www.internetworldstats.com/stats5.htm.

Jensen, R. J. (2006). Analyzing social movement rhetoric. Rhetoric Review, 25(4), 372-375.

Jones, Q., Grandhi, S. A., Karam, S., Whittaker, S., Zhou, C., \& Terveen, L. (2007). Geographic 'place' and 'community information' preferences. Computer Supported Cooperative Work, 17(2-3), 137-167. http://dx.doi.org/10.1007/s10606-007-9038-3 
Kennedy, J., \& Weimann, G. (2011). The strength of weak ties. Terrorism and Political Violence, 23(2), 201-212. http://dx.doi.org/10.1080/09546553.2010.521087

Khamis, S., \& Šisler, V. (2010). The new Arab cyberscape: Redefining boundaries and reconstructing public spheres. In C. T. Salmon (Ed.), Communication year book, 34 (pp. 277-316). New York, NY: Routledge.

Kock, N. (2009). Information systems theorizing based on evolutionary psychology: An interdisciplinary review and theory integration framework. MIS Quarterly, 33(2), 395-418.

Kozinets, R. V., de Valck, K., Wojnicki, A. C., \& Wilner, S. J. S. (2010). Networked narratives: Understanding word-of-mouth marketing in online communities. Journal of Marketing, 74(2), 71-89. http://dx.doi.org/10.1509/jmkg.74.2.71

Kuran, T. (1989). Sparks and prairie fires: A theory of unanticipated political revolution. Public Choice, 61(1), 41-74.

Kuran, T. (1995). The inevitability of future revolutionary surprises. American Journal of Sociology, 100(6), 1528-1551.

Lee, L. (1997). Similarity-based approaches to natural language processing (Technical Report TR-11-97). PhD thesis, Computer Science, Harvard University.

Lee, L. (1999, June). Measures of distributional similarity. In Proceedings of the 37th Annual Meeting of the Association for Computational Linguistics on Computational Linguistics (pp. 25-32). San Francisco: Morgan Kaufmann.

Lee, R., Wakamiya, S., \& Sumiya, K. (2011). Discovery of unusual regional social activities using geo-tagged microblogs. World Wide Web, 14(4), 321-349. http://dx.doi.org/10.1007/s11280-011-0120-x

Lee, S., Kim, J. H., \& Rosen, D. (2009). A semantic network and categorical content analysis of internet and online media research. The Open Communication Journal, 3, 15-28.

Li, N., \& Wu, D. D. (2010). Using text mining and sentiment analysis for online forums hotspot detection and forecast. Decision Support Systems, 48(2), 354-368. http://dx.doi.org/10.1016/j.dss.2009.09.003

Li, W. (1992). Random texts exhibit Zipf's-law-like word frequency distribution. IEEE Transactions on Information Theory, 38, 1842-1845. http://dx.doi.org/10.1109/18.165464

Lin, D. (1998a, July). An information-theoretic definition of similarity. In Proceedings of the Fifteenth International Conference on Machine Learning (pp. 296-304). San Francisco: Morgan Kaufmann.

Lin, D. (1998b). Automatic retrieval and clustering of similar words. In ACL '98 proceedings of the 36th annual meeting of the Association for Computational Linguistics and 17th international conference on computational linguistics (Vol. 2, pp. 768-774). Stroudsburg, PA: Association for Computational Linguistics.

Luck, T. (2011, August 4). With Arab Spring in full bloom, Jordan's jihadists look to turn new leaf. Jordan Times online. Available: http://www.jordantimes.com/?news=40119

Lundblad, J. P. (2003). A review and critique of Rogers' diffusion of innovation theory as it applies to organizations. Organization Development Journal, 21(4), 50-64.

Manson, S. M. (1981). Land use in the southern Yucatán peninsular region of Mexico: Scenarios of population and institutional change. Computers, Environment and Urban Systems, 30, 230-253. http://dx.doi.org/10.1016/j.compenvurbsys.2005.01.009

Marquette, J. F. (1981). A logistic diffusion model of political mobilization. Political Behavior, 3, 7-30.

Matsumura, N., \& Sasaki, Y. (2007). Human influence network for understanding leadership behavior. International Journal of Knowledge-based and Intelligent Engineering Systems, 11, 291-300.

Meade, N., \& Islam, T. (2006). Modeling and forecasting the diffusion of innovation - A 25-year review. International Journal of Forecasting, 22, 519-525. http://dx.doi.org/10.1016/j.ijforecast.2006.01.005

Meeks, W. L., \& Dasgupta, S. (2004). Geospatial information utility: An estimation of the relevance of geospatial information to users. Decision Support Systems, 38, 47-63. http://dx.doi.org/10.116/S0167-9236(03)000076-9

Meyer, D. S. (2004). Protest and political opportunities. Annual Review of Sociology, 30, 125-145. http://dx.doi.org/10.1146/annurev.soc.30.012703.110545 
Mitchell, G. R. (2004). Public argument action research and the learning curve of new social movements. Argumentation and Advocacy, 40, 209-225.

Monge, P. R., \& Contractor, N. S. (1998). Emergence of communication networks. In F. M. Jablin, \& L. L. Putnam (Eds.), Handbook of organizational communication $\left(2^{\text {nd }}\right.$ ed., pp. 440-502). Thousand Oaks, CA: Sage.

Morozov, E. (2011). Technology's role in revolution: Internet freedom and political oppression. The Futurist, 45(4), 18-21.

Mullen, B., Migdal, M. J., \& Hewstone, M. (2001). Crossed categorization versus simple categorization and intergroup evaluations: A meta-analysis. European Journal of Social Psychology, 31, 721-736. http://dx.doi.org/10.1002/ejsp.60

Murphy, E. C. (2006). Agency and space: The political impact of information technologies in the Gulf Arab states. Third World Quarterly, 27, 1059-1083. http://dx.doi.org/10.1080/01436590600850376

Northedge, L. (2011, March). First steps. The World Today, 67(3), 4-7.

Ohsawa, Y., Soma, H., \& Matsuo, Y. (2002, May). Featuring web communities based on word co-occurrence structure of communications. ACM, 11th International WWW Conference, Honolulu, HI.

Olson, M. (1968). The logic of collective action. Boston, MA: Harvard University Press.

Osgood, C. E. (1969). On the whys and wherefores of E, P, and A. Journal of Personality and Social Psychology, 12, 194-199.

Papacharissi, Z. (2009). The virtual geographies of social networks: A comparative analysis of Facebook, LinkedIn and A Small World. New Media and Society, 11, 199-220.

Pontius, R. G., Jr., Boersma, W.,Castella, J. C., Clarke, K., de Nijs, T., et al. (2008). Comparing the input, output, and validation maps for several models of land change. The Annals of Regional Science, 42, 11-47.

Pontius, R. G., Jr., Thontteh, O., \& Chen, H. (2008). Components of information for multiple resolution comparison between maps that share a real variable. Environmental and Ecological Statistics, 15, 111-142. http://dx.doi.org/10.1007/s10651-007-0043-y

Qin, J., Zhou, Y., Reid, E., Lai, G., \& Chen, H. (2007). Analyzing terror campaigns on the internet: Technical sophistication, content richness, and web interactivity. International Journal of Human-Computer Studies, 65, 71-84. http://dx.doi.org/10.1016/j.ijhcs.2006.08.012

Rahwan, I., Sonenberg, L., Jennings, N. R., \& McBurney, P. (2007). Stratum: A methodology for designing heuristic agent negotiation strategies. Applied Artificial Intelligence, 21, 489-527. http://dx.doi.org/10.1080/08839510701408971

Rogers, E. M. (2003). Diffusion of innovations ( $5^{\text {th }}$ ed.). New York: Free Press.

Rogers, E. M., \& Kincaid, D. L. (1981). Communication networks: Toward a new paradigm for research. New York: Free Press.

Shaw, S. L., \& Yu, H. (2009). A GIS-based time-geographic approach of studying individual activities and interactions in a hybrid physical-virtual space. Journal of Transport Geography, 17, 141-149. http://dx.doi.org/10.1016/j.jtrangeo.2008.11.012

Song, C., Qu, Z., Blumm, N., \& Barabási, A. L. (2010). Limits of predictability in human mobility. Science, 327, 1018-1021. http://dx.doi.org/10.1126/science.1177170

Spitzberg, B. H. (2006). Toward a theory of computer-mediated communication competence. Journal of Computer-Mediated Communication, 11, 629-666. http://dx.doi.org/10.1111/j.1083-6101.2006.00030.x

Stein, L. (2009). Social movement web use in theory and practice: A content analysis of US movement websites. New Media and Society, 11(5), 749-771. http://dx.doi.org/10.1177/1461444809105350

Stephens, K. K. (2011). The successive use of information and communication technologies at work. Communication Theory, 17, 486-507. http://dx.doi.org/10.1111/j.1468-2885.2007.00308.x

Stohl, C., \& Stohl, M. (2007). Networks of terror: Theoretical assumptions and pragmatic consequences. Communication Theory, 17, 93-124. http://dx.doi.org/10.1111/j.1468-2885.2007.00289.x

Strodthoff, G. G., Hawkins, R.P., \&Schoenfeld, A. C. (1985). Media roles in a social movement: A model of ideology diffusion. Journal of Communication, 35, 134-153. 
Taleb, N. N., \& Blyth, M. (2011). The black swan of Cairo: How suppressing volatility makes the world less predictable and more dangerous. Foreign Affairs, 90(3), 33-39.

Tillema, T., Dijst, M., \& Schwanen, T. (2010). Face-to-face and electronic communications in maintaining social networks: The influence of geographical and relational distance and of information content. New Media and Society, 12, 965-983. http://dx.doi.org/10.1177/1461444809353011

van den Hooff, B., Groot, J., \& de Jonge, S. (2005). Situational influences on the use of communication technologies: A meta-analysis and exploratory study. Journal of Business Communication, 41, 4-27. http://dx.doi.org/10.1177/0021943604271192

Van Laer, J. (2010). Activists online and offline: The internet as an information channel for protest demonstrations. Mobilization: An International Journal, 15, 347-366.

Van Laer, J., \& Van Aelst, P. (2010). Internet and social movement action repertoires: Opportunities and limitations. Information, Communication and Society, 13, 1146-1171. http://dx.doi.org/10.1080/1369118100368307

Walther, J. B., \& Bazarova, N. N. (2008). Validation and application of electronic propinquity theory to computer-mediated communication in groups. Communication Research, 35, 622-645. http://dx.doi.org/10.1177/0093650208321783

Watts, D. J. (2004). The "new" science of networks. Annual Review of Sociology, 30, 243-270. http://dx.doi.org/10.1146/annurev.soc.30.020404.104342

Watts, D. J., \& Dodds, P. S. (2007). Influentials, networks, and public opinion formation. Journal of Consumer Research, 34, 441-458.

Wu, J., \& Lederer, A. (2009). A meta-analysis of the role of environment-based voluntariness in information technology acceptance. MIS Quarterly, 33, 419-A9.

Yin, L., Shaw, S. L., \& Yu, H. (2011). Potential effects of ICT on face-to-face meeting opportunities: A GIS-based time-geographic exploratory approach. Journal of Transport Geography, 19, 422-433. http://dx.doi.org/10.1016/j.jrrangeo.2010.09.007

Zhitomirsky-Geffet, M., \& Dagan, I. (2009). Bootstrapping distributional feature vector quality.Computational Linguistics, 35, 435-461.

Zimbra, D., Abbasi, A., \& Chen, H. (2010). A cyber-archaeology approach to social movement research: Framework and case study. Journal of Computer-Mediated Communication, 16, 48-70. http://dx.doi.org/10.1111/j.1083-6101.2010.01531.x

\section{(c)) EY}

This work is licensed under a Creative Commons Attribution 3.0 License. 